$\frac{200 / 19 / 199}{12 / 19}$

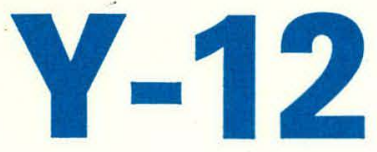

\section{OAK RIDGE $\mathrm{Y}-12$ PLANT}

\section{UNION} CARBIDE

\section{IASTER}

A NONCONTACT, LASER INTERFEROMETER SWEEP GAGE

W. E. Barkman

November 1979

\section{OPERATED BY}

UNION CARBIDE CORPORATION FOR THE UNITED STATES DEPARTMENT OF ENERGY 


\section{DISCLAIMER}

This report was prepared as an account of work sponsored by an agency of the United States Government. Neither the United States Government nor any agency Thereof, nor any of their employees, makes any warranty, express or implied, or assumes any legal liability or responsibility for the accuracy, completeness, or usefulness of any information, apparatus, product, or process disclosed, or represents that its use would not infringe privately owned rights. Reference herein to any specific commercial product, process, or service by trade name, trademark, manufacturer, or otherwise does not necessarily constitute or imply its endorsement, recommendation, or favoring by the United States Government or any agency thereof. The views and opinions of authors expressed herein do not necessarily state or reflect those of the United States Government or any agency thereof. 


\section{DISCLAIMER}

Portions of this document may be illegible in electronic image products. Images are produced from the best available original document. 
Reference to a company or product name does not imply approval or recommendation of the product by Union Carbide Corporation or the Department of Energy to the exclusion of others that may meet specifications.

Printed in the United States of America. Available from National Technical Information Service

U.S. Department of Commerce

5285 Port Royal Road, Springfield, Virginia 22161

Price: Printed Copy A02; Microfiche A01

This report was prepared as an account of work sponsored by an agency of the United States Government. Neither the United States Government nor any agency thereof, nor any of their employees, nor any of their contractors, subcontractors, or their employees, makes any warranty, express or implied, nor assumes any legal liability or responsibility for any third party's use or the results of such use of any information, apparatus, product or process disclosed in this report, nor represents that its use by such third party would not infringe privately owned rights. 
Distribution Category: UC-37

\title{
A NONCONTACT, LASER INTERFEROMETER SWEEP GAGE
}

\author{
W. E. Barkman
}

Fahrication Systems Department

$Y-12$ Development Division

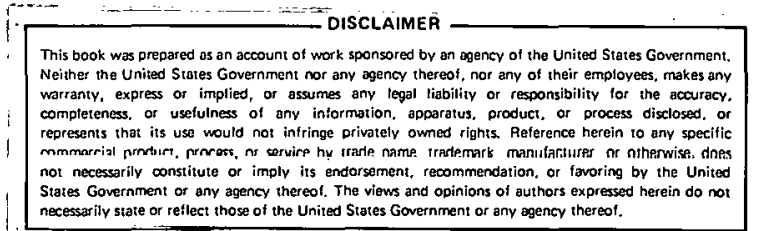

Oak Ridge Y-12 Plant

P. O. Box Y, Oak Ridge, Tennessee 37830

Prepared for the Department of Energy Under US Government Contract W-\%405-eng-26 


\section{ABSTRACT}

Parts that are manufactured with diamond tools on precision machines typically exhibit high-quality surfaces and contours; however, most materials that are diamond turned easily are also relatively soft and damage easily. Therefore, a noncontact, rotary inspection machine was developed. This machine utilizes a focused beam from a laser interferometer to measure variations in the surfaces of the reflective, spherical test parts used to characterize precision machines. Digital output data from the laser display is converted to an analog signal which is available for additional processing to provide contour and/or surface texture information. 


\section{CONTENTS}

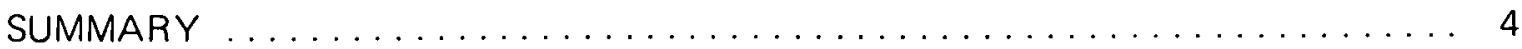

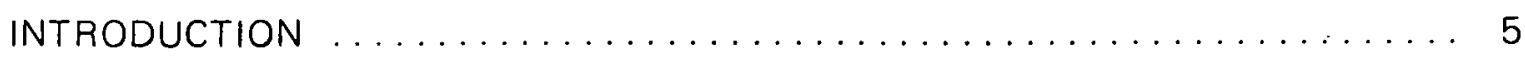

NONCONTACT, LASER INTERFEROMETER SWEEP GAGE $\ldots \ldots \ldots \ldots \ldots 6$

Description of the Inspection Machine $\ldots \ldots \ldots \ldots \ldots \ldots \ldots \ldots \ldots \ldots$

Gage Components ............................ 8

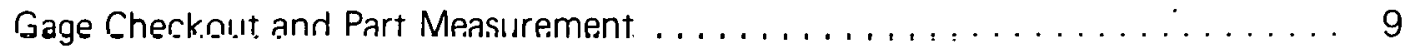

Discussion .................................... 10

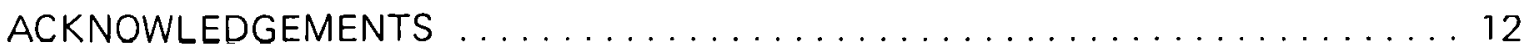

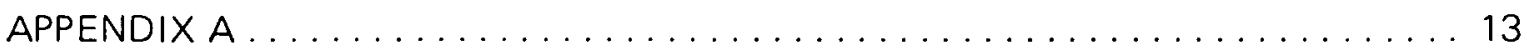

Laser Sweep Gage Master Sequence $\ldots \ldots \ldots \ldots \ldots \ldots \ldots \ldots \ldots \ldots \ldots \ldots$

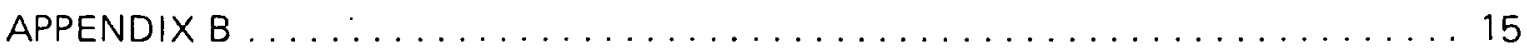

Alignment Procedure for Laser Interferometer and Optics ............... 15 


\section{SUMMARY}

Parts that are manufactured with diamond tools on precision machines typically exhibit high-quality, surfaces and contours. One technique for characterizing these machines is to fabricate a spherical test part from the material of interest so that the multiaxes contouring capability can be evaluated. Because most materials that can be diamond turned easily are also damaged easily, a noncontact, rotary inspection machine has been developed that utilizes a focused beam from a laser interferometer to measure perturbations in the surface of reflective parts. Digital output data from the laser display is converted to an analog signal that is available for additional processing to provide contour and/or surface texture information. A mastering sequence is also available that utilizes an air-bearing linear variable differential transformer (LVDT) to permit noncontact measurement of part size. 


\section{INTRODUCTION}

Parts that exhibit surface finishes of less than $250 \mathrm{~nm}(10 \mu \mathrm{in})$ peak to valley are produced on precision, diamond-turning machines. These parts may be special optical components or simply hemishell test pieces used to evaluate the capability of a particular machine tool. In either case, noncontact methods of part characterization are desirable both to protect the quality of the finished part and to avoid the uncertainties associated with the interface between the stylus and part surface.

Special techniques presently exist for the inspection of these high-quality parts; however, each of the methods has some inherent disadvantages. Air-bearing linear variabledifferential-transformer (LVDT) gage heads are used successfully to characterize high-quality diamond-turned parts. However, it is necessary to fine tune these gaging systems to achieve a stylus force that is sufficient to track the part surface accurately, and to maintain a good response characteristic without marring the surface by "plowing through" an irregularity. Capacitance gages are used as noncontact transducers but have a limitation; as the spot size of interest decreases so does the standoff distance, thereby increasing the likelihood of inadvertently contacting and scratching the part. Optical techniques are quite useful in the evaluation of part quality through the interpretation of fringe patterns; but it is difficuit to extract information about the various wavelengths present, as is required in the evaluation of precision machine tools.

The noncontact, laser interferometer sweep gage; developed at the Oak Ridge Y-12 Plant, (a) combines the high-accuracy sweep of the precision stylus instrument with the noncontact features of the capacitance gage and optical techniques. It presents neither the part-damage potential nor the limitation on the evaluation of specific wavelengths associated with gaging methods previously discussed.

(a) Operated by the Union Carbide Corporation's Nuclear Division for the Department of Energy. 


\section{NONCONTACT, LASER INTERFEROMETER SWEEP GAGE}

\section{DESCRIPTION OF THE INSPECTION MACHINE}

The laser interferometer sweep gage is shown in Figures 1 and 2. It consists of a base that was fabricated as a metal casting, a precision air-bearing table for rotating parts, an air-bearing quill slide used to position a linear-variable-differential-transformer gage head (LVDT) in the horizontal plane, an air-bearing quill that can be moved vertically as well as rotated, and the laser-interferometer equipment with the associated optics-positioning slides. Spherical parts with diameters up to $190 \mathrm{~mm}$ ( $7.5 \mathrm{in}$ ) can be inspected using the focused laser beam, while circular items such as diamond tools or nonreflective parts can be inspected using the low-gage-force air-bearing LVDT (see Figure 3).

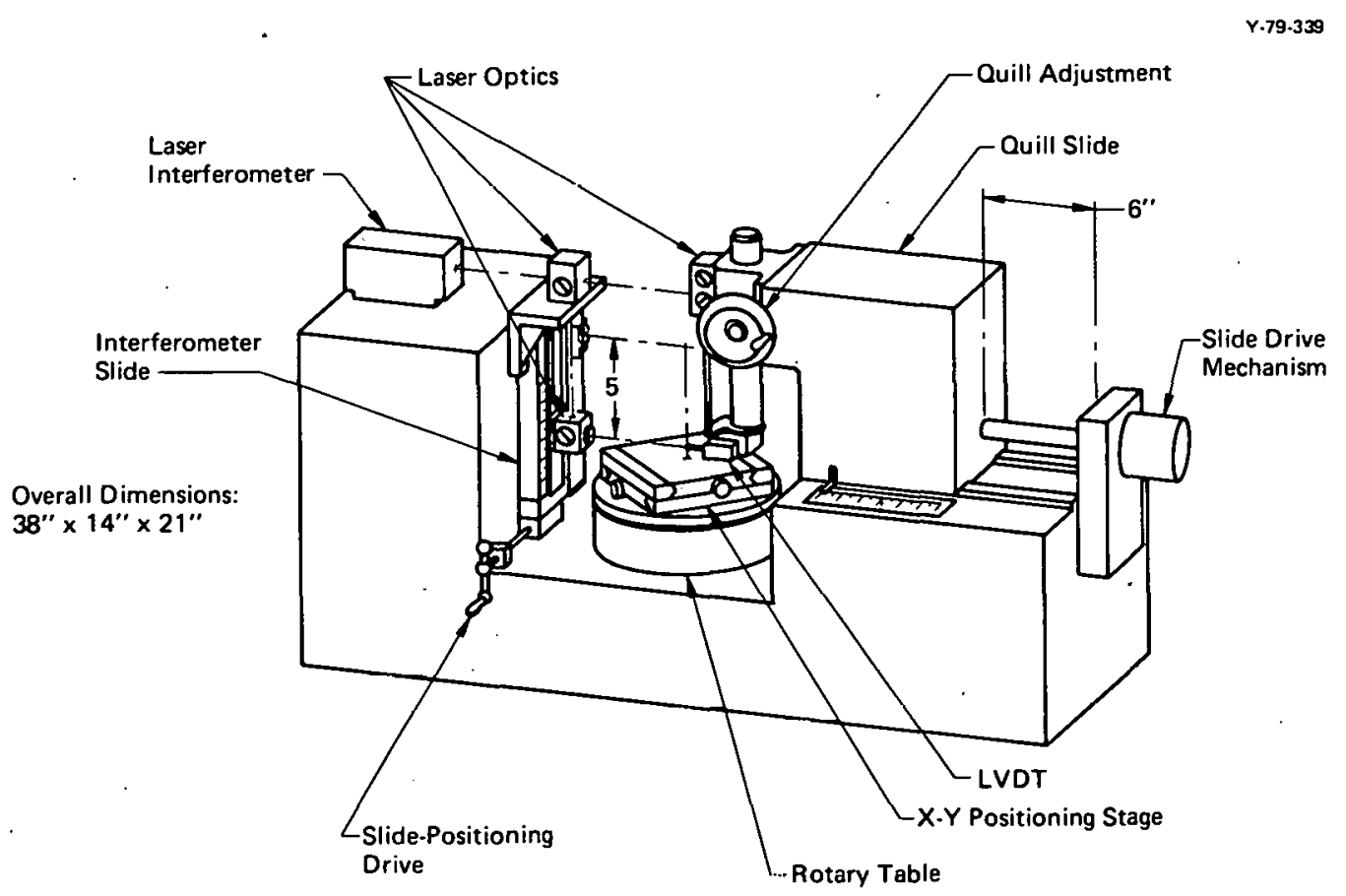

Figure 1. SKETCH OF NONCONTACT INSPECTION MACHINE.

The radius of a particular part is determined by using the air-bearing LVDT in conjunction with a master part consisting of gage blocks or other reference such as a precision ball. After nulling the LVDT on the reference surface, the radius of a part can be determined by again nulling the LVDT at the desired location and comparing the quill-slide laser-display reading at the point of interest with the display reading obtained on the reference surtace. However, care must be exercised in determining the distance from the rotary-table centerline to a point in space for maximum measurement accuracy. The reason is that the rotary-table plane of rotation and the line describing the direction of the quill-slide travel are not parallel. The tilt between the two axes produces an angular error of $15 \mu \mathrm{m} / \mathrm{m}(15 \mu \mathrm{in} / \mathrm{in})$; therefore the gage should be mastered with the LVDT near the same vertical location as the point of interest on the part surface. This also eliminates any potential errors encountered 


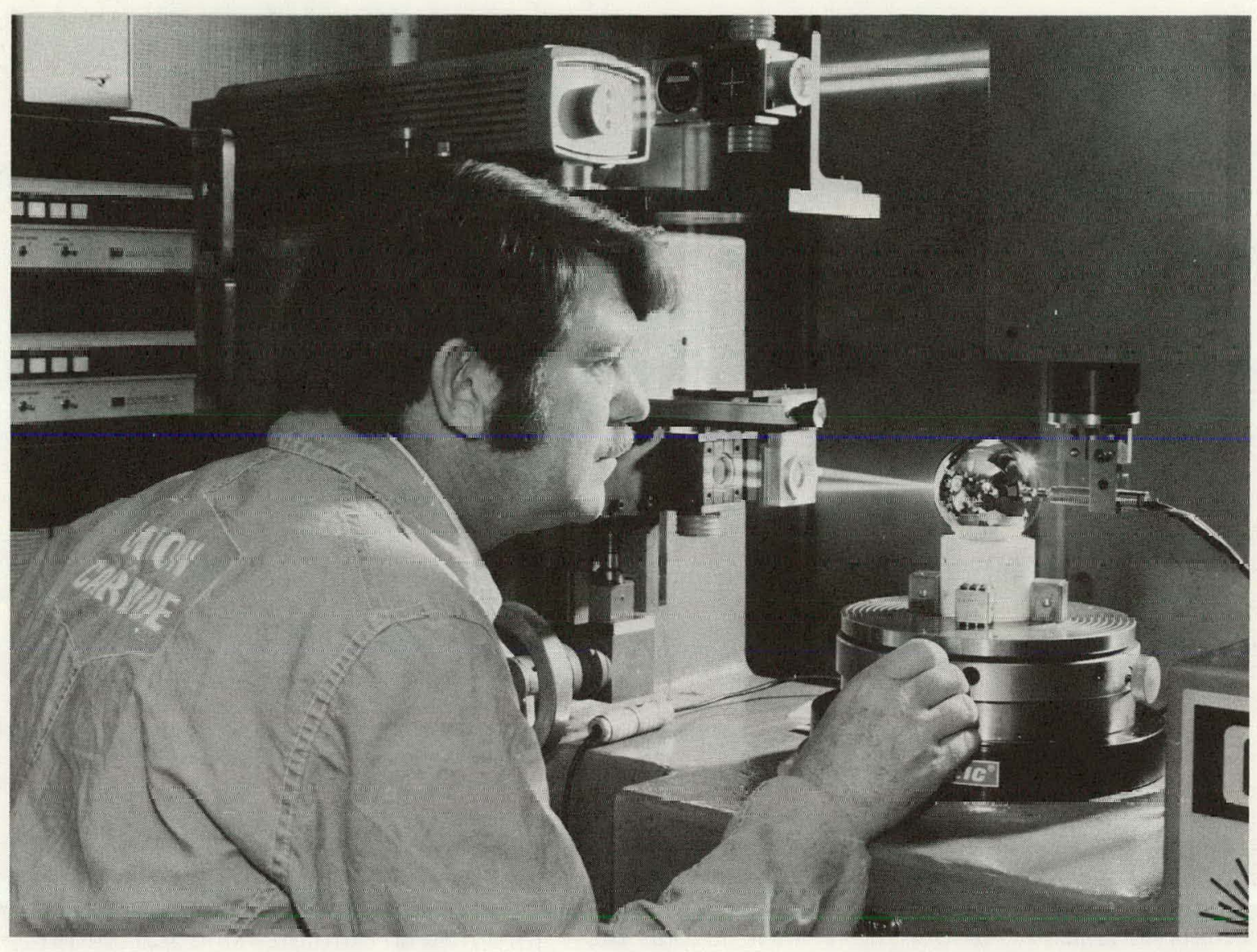

Figure 2. NONCONTACT INSPECTION MACHINE WITH PRECISION TEST PART.

186874

due to the lack of straightness of the vertical-quill-slide travel. The angular error in the orthogonal direction is not so critical since it is the insensitive direction. The error is approximately $100 \mu \mathrm{m} / \mathrm{m}$ (100 $\mu \mathrm{in} / \mathrm{in})$ and corresponds to a size error of less than $75 \mathrm{~nm}$ (3 $\mu \mathrm{in})$ per $25 \mathrm{~mm}$ ( $1 \mathrm{in}$ ) of vertical displacement when inspecting a $0.53 \mathrm{~mm}$ (0.021 in) radius. The side-to-side misalignment of the rotary-table centerline and the quill centerline is approximately $6.35 \mu \mathrm{m}(250 \mu \mathrm{in})$ at the rotary-table face; however, the misalignment decreases at increasing distances above the tabletop as a result of the angular tilt between the axes.

Before a particular part can be inspected, it must be aligned on the rotary table. An initial, visual attempt at alignment is followed by focusing the laser beam onto the part surface; and final alignment is obtained using the laser display. Following alignment, the part is rotated until the desired reference point is coincident with the focused laser beam. Then the rotary table is used to rotate the part past the focused laser beam thereby providing the means for the measurement of contour, concentricity, and surface texture. When the mastering sequence is utilized, size information is also available. 
The air-bearing LVDT is not used to sweep the part, but it must make point contact with the part to provide a null location during the mastering sequence. Normally, the angular location of the air-bearing quill is adjusted during the initial setup to ensure that the LVDT contacts the part on the horizontal centerline. For single-point measurements, only the quill angle that gives the maximum LVDT deflection must be established since the transducer is being used only as a null device. For sweep measurements, however, it may also be desirable to align the LVDT direction of travel parallel to the quill slide and to adjust the LVDT side-to-side location lusing the reed bracket that attaches the LVDT to the quill) so that the LVDT tip is aligned with the centers of rotation of the air-bearing rotary table and quill. Fortunately, these adjustments are not critical because the scale factor, in effect, is determined prior to

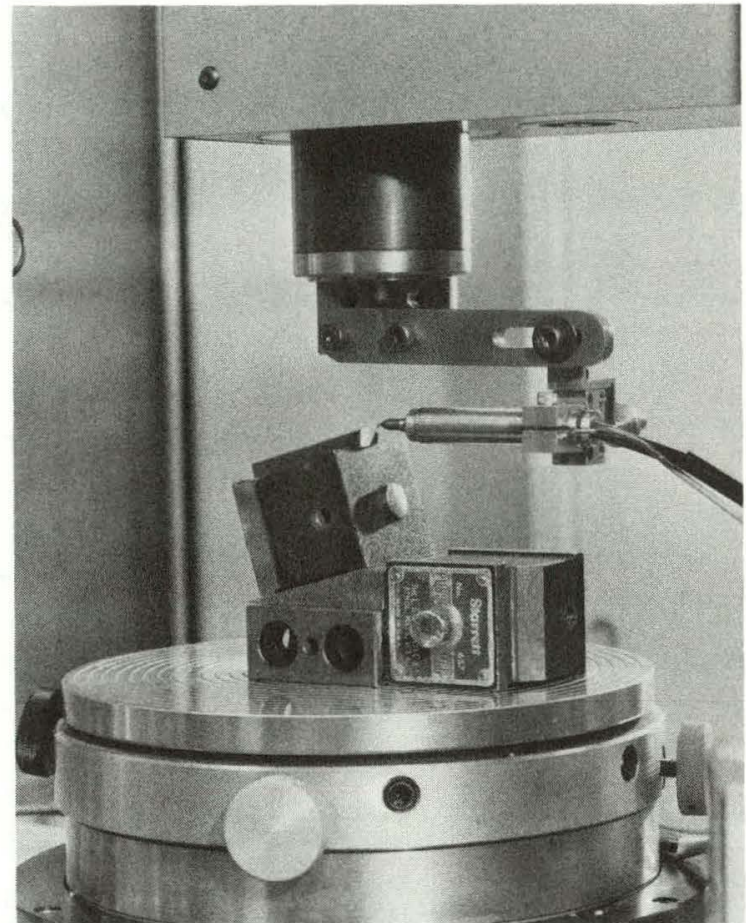

185985 Figure 3. SETUP USED FOR CERTIFYING DIAMOND TOOLS. part inspection. A more-detailed mastering sequence is required for "small" radii such as those encountered with diamond tools. In this instance the mastering sequence listed in Appendix A can be used.

Following the side-to-side and angular adjustments (in order to avoid possible damage to the surface finish), it may be necessary to set the vertical height of the LVDT prior to part inspection. If the quill slide cannot be moved vertically (to locate the part centerline) while the LVDT is in contact with the part, then it is necessary to use a dummy part of the same size to establish proper location. After these adjustments are made, it is necessary to move (in a radial direction only) the LVDT on and off the part using the linear axis to establish the desired reference location. For parts that are not easily scratched, the setup can be made on the actual part.

\section{Gage Components}

The sweep gage utilizes standard off-the-shelf air-bearing components and laserinterferometer optics. The $203 \mathrm{~mm}(8 \mathrm{in})$ rotary table exhibits a radial and axial accuracy of $\pm 25 \mathrm{~nm}( \pm 1 \mu \mathrm{in})$, while the quill-slide straightness is $0.51 \mu \mathrm{m}(20 \mu \mathrm{in})$. The vertical-quill straightness is also $0.51 \mu \mathrm{m}(20 \mu \mathrm{in})$. The resolution of the laser displays is $0.01 \mu \mathrm{m}$ or $1 \mu \mathrm{in}$, while the up/down displacement pulses (provided by the noncontact-measurement display) have a resolution of $1 / 40$ of the laser wavelength or approximately $16 \mathrm{~nm}(0.6 \mu \mathrm{in})$. These pulses, which represent variations in the part surface, are summed and converted into an analog signal that can be filtered and recorded on a polar or strip chart. 
The two-axes laser interferometer is used with a beam splitter to measure both the horizontal quill-slide position and perturbations in the reflective surface of the part. One beam from the splitter is passed to a plane-mirror interferometer that is used to detect quill-slide movement. The other beam is sent to a linear interferometer, focused, and reflected off the part surface. Appendix $B$ describes the procedure used to align the laser and optics on the inspection machine.

The diameter of the focused beam is a function of the focal length of the lens used, and two separate lenses with focal lengths of $0.127 \mathrm{~m}(5 \mathrm{in})$ and $0.254 \mathrm{~m}(10 \mathrm{in})$ were chosen to provide total coverage of the gage part-size capacity without requiring excessive travel from the lens-positioning slide. The focused-beam diameter of the $0.127 \mathrm{~m}$ lens is $10 \mu \mathrm{m}$ $(0.0004 \mathrm{in})$, while the spot size associated with the $0.254 \mathrm{~m}$ lens is $20 \mu \mathrm{m}(0.0008 \mathrm{in})$. The respective depths of field of the two lenses are $1.0 \mathrm{~mm}(0.040 \mathrm{in})$ and $4 \mathrm{~mm}(0.16 \mathrm{in})$. Dust or scratches on the part surface can result in problems with the smaller beam. While the dust can be easily removed, it may be necessary to utilize segmented testing to overcome the loss of beam alignment at certain locations on a part surface. Ideally there should be no scratches or other imperfections on a finished precision part.

A $10 \times$ resolution extender is used in the part-measurement loop to obtain a nominal output-pulse value of $16 \mathrm{~nm}(0.6 \mu \mathrm{in})$. (A $10 \mathrm{X}$ resolution extender is used also with the quill-axis measurement to obtain the $0.01 \mu \mathrm{m}$ or $1.0 \mu \mathrm{in}$ display resolution.) Unfortunately, the use of the extender precludes the use of a single-bejam interferometer for making the noncontact measurements because of instability problems in the resultant laser system. However, the angular errors introduced by using the linear interferometer are quite small as shown in Figure 4.

\section{Gage Checkout and Part Measurement}

Gage stability and repeatability checks were conducted prior to using the gage for certification measurements. These tests were ronndusterd to evaluate the paths between the laser optics and the part, as

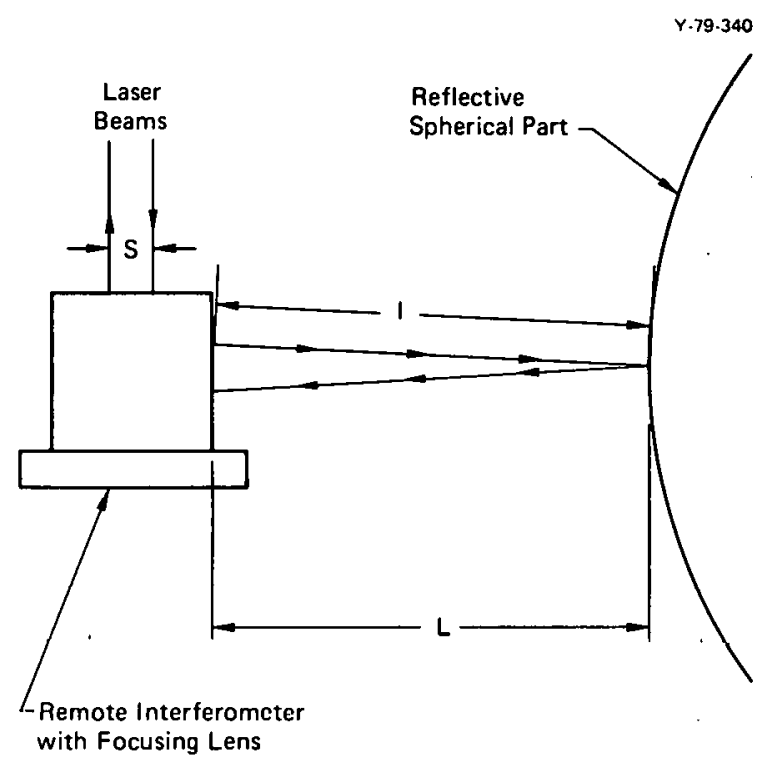

Figure 4. CALCULATION OF ERROR AS A RESULT OF FOCUSED LASER BEAM. (For the Beam Spacing, $\mathbf{S}=$ $12.7 \mathrm{~mm}(0.5 \mathrm{in})$ and a focal length $L$ of $127 \mathrm{~mm}(5 \mathrm{in})$, the laser path length between the lens and surface is $127.15865 \mathrm{~mm}(5.006246 \mathrm{in})$. If $L$ increases to 127.0254 $\mathrm{mm}(5.001 \mathrm{in})$, then $\mathrm{f}=127.18402 \mathrm{~mm}(5.00724 \mathrm{in})$, for a measured length change of $25.37 \mu \mathrm{m}$ (U.uUuyyy in) or approximately $0.1 \%$ error.] well as between the quill LVDT and the part. The:path (from the remote interferometer and focusing lens to the part mounted on the rotary table) exhibited a noise level of \pm 2 output counts or $\pm 32 \mathrm{~nm}( \pm 1.2 \mu \mathrm{in})$ with a 24-hour stability of about $254 \mathrm{~nm}(10 \mu \mathrm{in})$. The path (from the plane-mirror interferometer to the quill slide) showed a 24-hour stability of $\sim 381 \mathrm{~nm}(15 \mu \mathrm{in})$ without an air supply to 
the quill slide and $\sim 1 \mu \mathrm{m}(40 \mu \mathrm{in})$ with an air supply. However, this factor is not critical as long as the laser accurately infers the LVDT position by monitoring the location of the quill slide.

The background noise level for this axis was $\pm 2-3$ counts or $\pm 16-23 \mathrm{~nm}( \pm 0.6-0.9 \mu \mathrm{in})$ without air and $\pm 5-10$ counts or $0.6-1.3 \mu \mathrm{m}(1.5-3.0 \mu \mathrm{in})$ with air. The higher amplitude of noise encountered with the quill-slide air supply on is due to building structural vibration being conducted through the thin air film. Fortunately, this oscillation is at a frequency. $(60 \mathrm{~Hz})$ that allows accurate measurements to be obtained using the averaging feature of the laser display.

Pitch tests were conducted on the gage linear axis using the laser with an angular interferometer. The measured pitch over the $150 \mathrm{~mm}$ (6 in) travel path of the axis was approximately 0.4 arc seconds. This angular motion results in a potential error of about $0.6 \mu \mathrm{m}(24 \mu \mathrm{in})$ when coupled with the nominal 300-mm (12-in) Abbe offset between the plane mirror and the LVDT. Fortunately, the pitch error of the axis is relatively gradual and results in errors of less than $5 \mu \mathrm{m} / \mathrm{m}(5 \mu \mathrm{in} / \mathrm{in})$ over most of the slide travel. This allows accurate measurements to be made when the gage is mastered at a location near the radius of interest.

Measurement repeatability checks were conducted using two diamond-turned solid-copper balls. One of the nominal $50-\mathrm{mm}$ (2-in) diameter balls was arbitrarily chosen as a reference master, and the other was used as a test part. After mastering the gage with the first ball, multiple measurements were made using the second ball to determine the repeatability of size measurements. The test data indicate a total spread of $0.46 \mu \mathrm{m}(18 \mu \mathrm{in})$ with a standard deviation of $0.14 \mu \mathrm{m}(5.6 \mu \mathrm{in})$ about the mean. Actual gage accuracy depends on both the repeatability and accuracy of the mastering sequence.

\section{Discussion}

The extensive use of the laser interferometer on this noncontact inspection machine provides the potential for a high degree of accuracy and sophistication in establishing the characteristics of precision parts. However, in order to utilize the capabilities of the laser system, it is necessary to use care in the alignment of the laser head and the associated optics. The laser beam must be aligned parallel to the machine's linear axis and also must intersect the centerline of the rotary table. The first requirement is necessary to avoid cosine errors in the determination of the horizontal quill-slide position. The second condition is required to avoid repositioning the laser optics associated with the part-measurement loop each time the part size is significantly changed.

Noncontact measurements can be obtained by focusing the laser beam either on the part surface or on the center of the rotary table. While the center-focusing technique avoids the necessity of lens-position readjustment each time the part size is changed, it also results in a varying spot size as well as a significantly larger spot. The surface-focusing technique provides a more suitable framework for surface-texture measurements, although laser-beam alignment can be lost as a result of surface imperfections. 
The surface-texture information is obtained by filtering the analog signal from either the LVDT (contact measurements) or from the digital-to-analog (D/A) converter associated with the laser (noncontact measurements). The filtering technique used to date depends on analog filters operating in the Butterworth mode. Unfortunately, with such a system it is difficult to differentiate between system noise and actual signals; and potential problems due to signal phase shift within the filters may be encountered.

Future efforts will include the utilization of a digital-signal analyzer in an attempt to differentiate between background noise and the actual signal and also to provide a means to determine the amplitudes of specific wavelengths. Digital filtering techniques will also be investigated in an attempt to avoid other phase-shift problems associated with analog filters. (b)

(b) Feezell, R. R. and Marcum, R. C.; Elimination of Phase Distortion in Filters Using Digital Techniques, Y-DA-3514; Union Carbide Corporation-Nuclear Division, Oak Ridge Y-12 Plant, Oak Ridge, Tennessee; May 12, 1970. 


\section{ACKNOWLEDGEMENTS}

The author would like to express appreciation to W. H. Chapman, Lawrence Livermore Laboratory, for his help in acquiring the various components of the noncontact, rotary inspection machine; to S. B. McSpadden, Jr and W. H. Rasnick for their help in developing a mastering technique for use with diamond tools; and to R. R. Williams for his continued assistance in integrating the gaging concept and the hardware into a useful machine. 


\section{APPENDIX A}

\section{LASER SWEEP GAGE MASTER SEQUENCE}

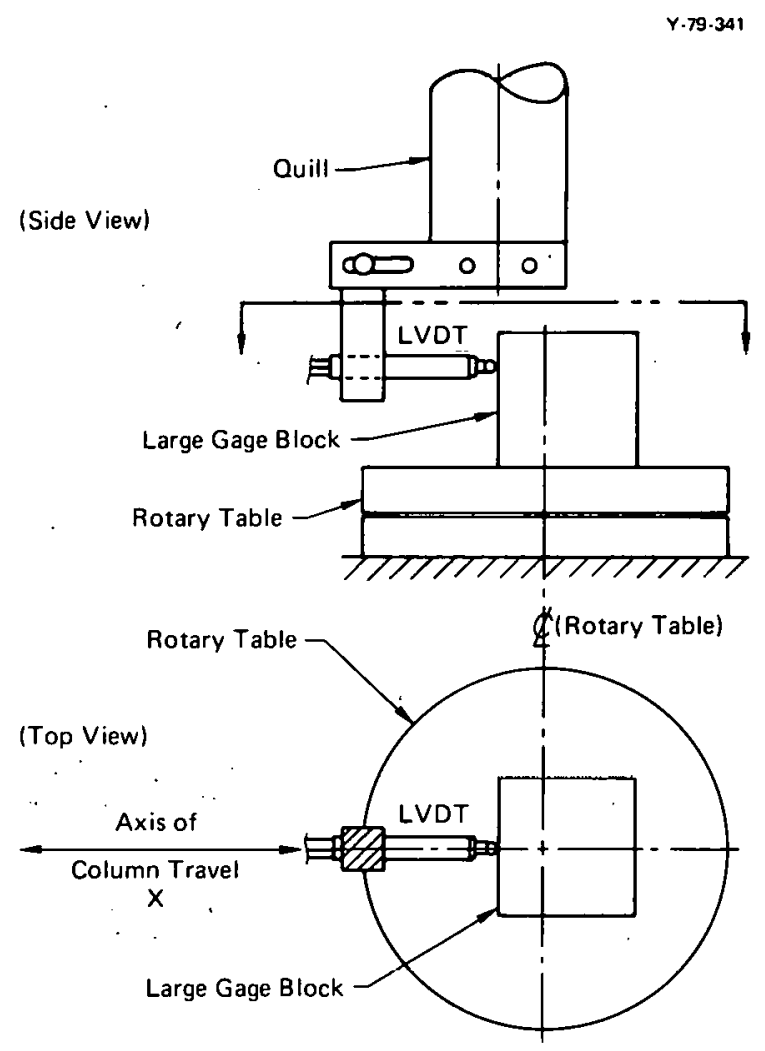

Figure A-1. LASER GAGE QUILL AND ROTARY TABLE.

1. Level rotary table top by rotating the table and measuring runout with a fixed 0.0001 -inch indicator. Adjust leveling knobs to achieve minimum runout.

2. Position the LVDT so that its null position coincides approximately with the quill centerline (refer to Figure A.11.

a. Place a large gage block on the rotary table so that one flat surface lies perpendicular $(1)$ to the axis of column travel $X$.

b. Adjust the lateral position of the LVDT until the LVDT "nulls out" against the gage block when the LVDT centerline is parallel to the $X$ axls.

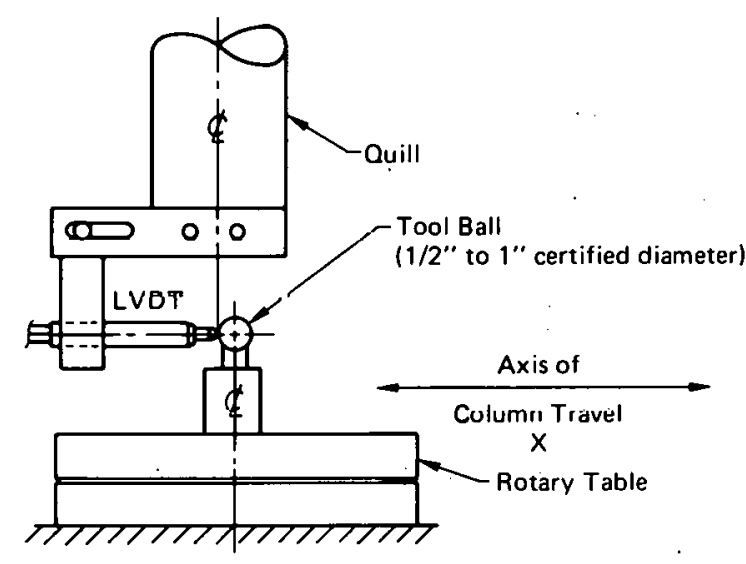

Figure A-2. LASER GAGE QUILL AND ROTARY TABLE.

3. Refer to Figure A-2.

DO NOT MOVE THE QUILL OR THE LVDT.

a. Move the column away from the rotary-table centerline.

b. Position a certified-diameter tool ball in the center of the rotary table: rotate the table, and use the LVDT position readout to center the tool ball.

c. Zero the column-position indicator lights with the LVDT "nulled out" against the tool ball.

d. Remove the tool ball, and move the column toward the rotary table one-half $(1 / 2)$ the diameter of the tool ball. (Use the position indicator lights.) Rezero the position indicator lights.

Note: Steps 1, 2, and 3 have established the table centerline with respect to the LVDT null position. assuming the quill is not moved. However, the LVDT null position still does not coincide precisely with the quill centerline. Proceed to Step 4. 


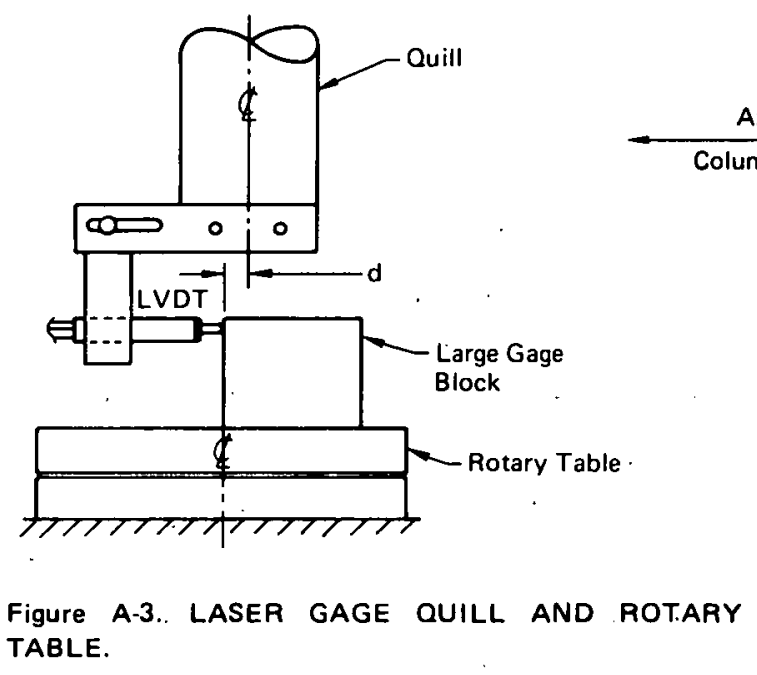

4. Refer to Figure A-3.

DO NOT MOVE THE QUILL OR THE LVDT.

a. Place a large gage block on the rotary table with one flat surface coincident with the table centerline and the LVDT null point.

b. Adjust the position of the gage block until the flat surface is perpendicular to the axis of column travel (Obtain the null reading on the LVDT by rotating the table, NOT the quill.).

c. DO NOT MOVE THE ROTARY TABLE ONCE THE NULL READING HAS BEEN ESTABLISHED.
Axis of

$\mathrm{x}$

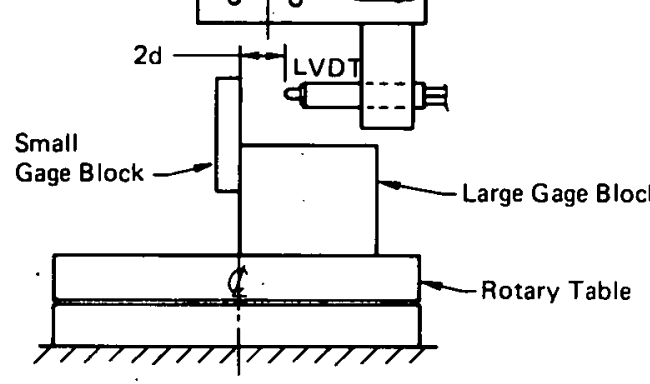

Figure A-4. LASER GAGE QUILL AND ROTARY TABLE.

5. Refer to Figure A-4.

a. Raise the quill and rotate it 180 degrees.

b. Wring a small gage block to the large gage block. being careful not to move either the rotary table or the large gage block.

c. Move the column until the LVDT "nulls out" against the small gage block. (This distance is equal to "2d.")

d. Move the column a distance equal to " $d$ " in the opposite direction, and zero the positionindicator lights.

e. Loosen the LVDT mounting bracket, and carefully move the LVDT until it "nulls out" against the small gage block.

Note: Steps 2.a through 5.e should be repeated until the distance " $d$ " (see Figure A-3) in Step 5.d becomes insignificant. 


\section{APPENDIX B}

\section{ALIGNMENT PROCEDURE FOR LASER INTERFEROMETER AND OPTICS}

This procedure applies specifically to the noncontact, laser interfermeter sweep gage and assumes a basic familiarity with the laser-interferometer-alignment techniques described in the Hewlett-Packard manuals.

1. Align laser beam parallel to the direction of travel of the linear quill-slide axis, and adjust the beam position to intersect the center of the rotary table.

2. Mount beam splitter, plane-mirror interferometer, and plane mirror. Adjust position of optics so that both reference and measurement beams return to the upper return port on the laser head. Fine adjust position of optics for maximum beam alignment.

3. Mount focusing lens onto small focusing slide, and ensure that this slide travel is parallel to the linear quill slide.

4. Align reflective spherical part on rotary table.

5. Mount linear interferometer on main optics slide. Adjust position of interferometer and slide so that both reference and measurement signal beams return to the lower return port on the laser head. Adjust the focusing lens and linear interferometer for maximum beam alignment.

6. Verify that alignment is correct for all potential part sizes, ie, adjust only the two optics slides to obtain beam alignment after the part is aligned on the rotary table. 


\section{Distribution}

Department of Energy - Oak Ridge

Hickman, H. D.

Leed, R. E.

Poteat, R. M:

Lawrence Livermore Laboratory

Arnold, W. F.

Los Alamos Scientific Laboratory

Hoyt, H. C.

Oak Ridge Gaseous Diffusion Plant

Armstrong, R. C: :

Stief, S. S.

Wilcox, W. J., Jr

Oak Ridge National Laboratory

Hopkins, C. C.

Oak Ridge $Y-12$ Plant

Alvey, H. E.

Anderson, P. J.

Barkman, W. E. (25)

Burditt, R. B.

Dawson, D. O.

Dodson, W. H./Googin, J. M.

Douglass, S. S.

Fruaseèr, K. J.

Gerth, H. L.

Hewgley, R. E., Jr

Hurst, J. S.

Keith, A.

Kite, H. T. (30)

Mills, J. M., Jr

Phillips, L. R.

Rasnick, W. H.

Steger, P. J.

Thompson, C. H.

Whitten, L. G., Jr

Wright, C. C.

$Y-12$ Central Files (master copy)

$Y-12$ Central Files (route copy)

$Y-12$ Central Files ( $Y-12 R C)$

$Y-12$ Central Files (5)

\section{Paducah Gaseous Diffusion Plant}

Bewley, H. D.

Sandia - Livermore

Spencer. W. J.

Union Carbide Corporation - New York

Tinsley, S. $w$.

In addition, this report is distributed in accordance with the Category UC-37, Instruments, as given in the Standard Distribution for Unclassified Scientific and Technical Reports, DOE/TIC-4500. 